\title{
Desafios a superar no ambiente de pesquisa no Brasil
}

\author{
Luiz Vicente Rizzo - Hospital Israelita Albert Einstein - Instituto Israelita de Ensino e \\ Pesquisa
}

\begin{abstract}
Resumo
O desafio de manter pesquisa científica de alto nível no Brasil é focado em três pilares. O primeiro é organizacional, "put your money where your mouth is" Se uma instituição acredita que pesquisa é relevante para atividade médica os resultados esta área devem fazer parte das metas organizacionais. Aproximadamente $20 \%$ das metas no Balanced Score Card, que determina as gratificações da liderança são metas de ensino e pesquisa. O segundo é estrutural, a área de pesquisa oferece todo o apoio para a realização de estudos científicos, desde o apoio para a obtenção e gerenciamento de grants, até área, pessoal, material e suporte técnico para pesquisa translacional e pesquisa clínica. $O$ terceiro pilar é administrativo, o instituto gerencia as atividades de pesquisa utilizando entre outras ferramentas um software desenvolvido in house (I.Search) que permite o entendimento em tempo real de todas as atividades ligadas à ciência na instituição e consequentemente permitindo intervenções positivas sempre que diagnosticadas como necessárias através da leitura dos indicadores diários. Baseado nestes três pilares é possível vencer as grandes barreiras à pesquisa científica no Brasil que são de ordem burocrática. As dificuldades trabalhistas, os problemas com insumos e uma legislação que se move constantemente sem nenhuma política de estado.
\end{abstract}

Palavras chave: liderança,

Rizzo, Luiz Vicente. "Desafios a superar no ambiente de pesquisa no Brasil", in Anais do 20. Congresso Internacional Sabará de Especialidades Pediátricas 